\title{
Follow-up and nonpharmacological management of the idiopathic pulmonary
}

\section{fibrosis patient}

\author{
J.J. Egan
}

ABSTRACT: Idiopathic pulmonary fibrosis (IPF) is a chronic, progressive, fatal form of diffuse interstitial lung disease. Management of IPF requires an orderly approach, with regular evaluations and implementation of both pharmacological and nonpharmacological treatments. Pulmonary rehabilitation can relieve patients from the distressing symptoms of IPF and improve quality of life. Oxygen therapy is central to treatment of all patients. Lung transplantation enhances survival in selected patients. Mechanical ventilation may be used in patients with acute exacerbations, but the prognosis is poor in these cases. Palliative care focuses on symptom management, advance directives and end-of-life planning. Patient support groups may also play an important role.

KEYWORDS: Idiopathic pulmonary fibrosis, lung allocation score, lung transplantation, oxygen therapy, palliative care, pulmonary rehabilitation

diopathic pulmonary fibrosis (IPF) is a chronic, progressive, fatal form of diffuse interstitial lung disease which is associated with substantial mortality and morbidity $[1,2]$. It accounts for nearly $30 \%$ of lung transplantation procedures performed worldwide [3]. The disease is usually characterised by gradual onset of symptoms, with dyspnoea being the most prominent and the most disabling [4]. Risk factors associated with disease development include smoking, drug exposure, chronic aspiration, infectious agents and genetic predisposition [1].

The management of IPF requires a methodical approach with regular evaluations and the implementation of both pharmacological and nonpharmacological treatment strategies. Potential pharmacotherapy includes corticosteroids, immunosuppressive agents and/or antifibrotic agents [1]. Thus, it is important to consider what nonpharmacological interventions are available that might allow patients with IPF to optimise their quality of life [5].

\section{REHABILITATION}

Pulmonary rehabilitation has become the standard of care for chronic lung disease because of its effectiveness in alleviating symptoms, reducing the duration of hospital stays, increasing exercise tolerance and maximising functional ability $[6,7]$. Exercise rehabilitation has also been associated with positive psychosocial outcomes, including reduced symptoms of anxiety and depression [8].

Pulmonary rehabilitation in IPF has been associated with a statistically significant improvement in 6-min walk distance and dyspnoea [9], although the role of maintenance exercise programmes following the initial structured training remains unclear [10]. Patients should be educated with regard to the treatment and prevention of infections [11]. Patients undergoing lung transplantation are required to participate in preoperative and postoperative pulmonary rehabilitation. The programmes help physicians to select appropriate surgical candidates, and also prepare patients physically and psychologically for the stress of surgery [10].

Successful pulmonary rehabilitation may require behavioural changes on the part of the patient, including: weight loss, adoption of a regular exercise regime; learning how to use breathing techniques, pacing and energy conservation strategies; and understanding the use of medications, supplemental oxygen (see later) and associated equipment [10].
CORRESPONDENCE

J.J. Egan

Advanced Lung Disease Programme

Mater Misericordiae University Hospital Eccles Street

Dublin 7

Ireland

E-mail: jegan@mater.ie

Received:

Feb 142011

Accepted after revision:

April 132011

\section{PROVENANCE}

Publication of this peer-reviewed article was supported by InterMune Inc.,

Brisbane, CA, USA (article sponsor, European Respiratory Review issue 120).

Online ISSN 1600-0617 


\section{OXYGEN THERAPY}

Nocturnal hypoxaemia is common in patients with IPF and may have an impact on health-related quality of life. It is mainly associated with reduced energy levels and impaired daytime social and physical functioning [12]. There are no high-quality data demonstrating the benefit of supplemental oxygen therapy for patients with IPF [13]. However, it has been shown that daytime oxygen concentration is the best predictor of nocturnal hypoxaemia [12]. Therefore, it seems prudent to provide supplemental oxygen therapy for patients showing resting hypoxaemia or significant oxygen desaturation with exercise. In such patients, supplemental oxygen therapy is likely to improve symptoms and overall quality of life [14]. Supplemental oxygen has also been used during rehabilitative exercise training. In patients without exercise-induced hypoxaemia it may increase endurance during high-intensity exercise [10]. Therefore, oxygen therapy is a critical component of the management of IPF.

\section{TRANSPLANTATION}

The mean survival time for patients diagnosed with IPF is 2.5$3.5 \mathrm{yrs}$, with periods of rapid decline in the status of patient's health [15]. In one study, patients with IPF who received a lung transplant showed a $75 \%$ reduction in risk of death compared with patients who remained on the waiting list (fig. 1) [16] Risk of mortality while waiting for lung transplantation is significantly greater for patients with IPF compared with cystic fibrosis and emphysema [17]. Thus, lung transplantation has become one of the treatments of choice for patients with advanced IPF [18].

In the USA, the Organ Procurement and Transplantation Network (OPTN) prioritises transplant candidates based on the lung allocation score (LAS), which is calculated from estimates of survival probability [19]. Patients with high scores get priority. This has resulted in increased numbers of IPF patients undergoing lung transplantation. However, high LAS values are associated with decreased survival following lung transplantation, increased length of stay following transplantation, and

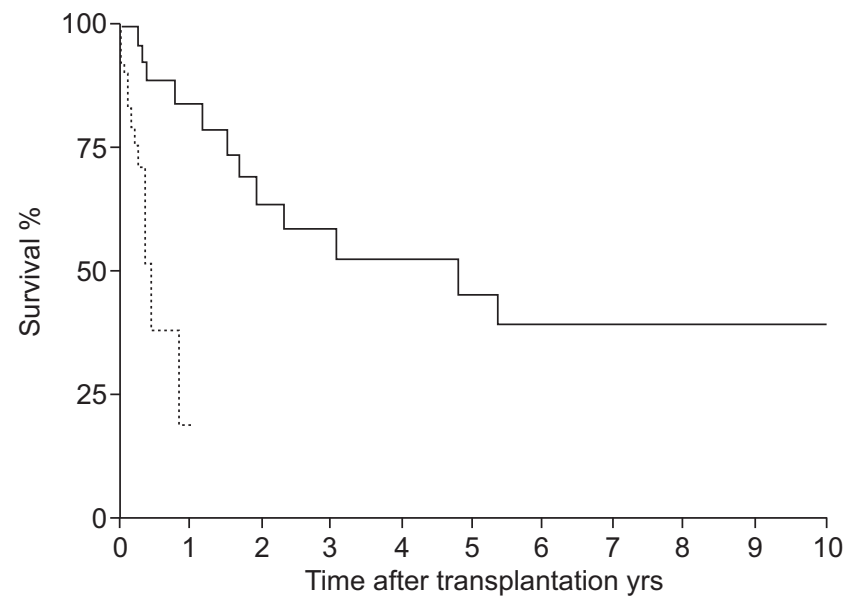

FIGURE 1. Survival on waiting list (from placement on the list to death or transplantation; $\cdots . . .$.$) ) compared with survival of patients who underwent lung$ transplantation (from placement on the list including post-transplantation survival; -). Reproduced from [16] with permission from the publisher higher rates of infection, renal failure and stroke [20]. The LAS allows physicians to: 1) improve survival by performing transplantation in patients with the highest mortality risk before transplantation, and 2) potentially to improve post-transplant survival by avoiding lung transplantation in patients who are unlikely to survive after transplantation [19]. Currently in Europe a scoring system is under discussion but many centres do give priority to IPF patients.

Pulmonary function tests (PFTs) are the cornerstone of current practice in the assessment of disease severity and progression. PFTs such as diffusing capacity of the lung for carbon monoxide (DL,CO), and per cent predicted forced vital capacity (FVC), are significant independent predictors for survival. Early mortality (within 2 yrs) is strongly linked to the severity of pulmonary function impairment (lower composite physiological index, FVC and DL,CO levels), and not to the histopathological diagnosis (table 1) [21]. Combination of variables ( $D \mathrm{~L}, \mathrm{CO}$ and high-resolution computed tomography fibrosis scores) in a Cox regression model has been shown to improve survival prediction [22].

The rate of disease progression, independent of the initial degree of disability, is important for determining prognosis. In $81 \mathrm{IPF}$ patients with median survival of $4.3 \mathrm{yrs}, 10 \%$ change in FVC at 6 months was found to be the best predictor of mortality [23]. International guidelines recommend that symptomatic patients with IPF aged younger than $65 \mathrm{yrs}$ should be referred for transplantation if there is a $D \mathrm{~L}, \mathrm{CO}$ of $<39 \%$ pred and/or evidence of a FVC decline of $\geqslant 10 \%$ over 6 months [24].

\section{MANAGEMENT OF ACUTE EXACERBATION OR RAPIDLY PROGRESSIVE IPF}

Acute exacerbation of IPF, which occurs in $10-50 \%$ of patients [25-27], is characterised by: 1) progressive dyspnoea over the

\begin{tabular}{|c|c|c|c|c|}
\hline \multirow[t]{2}{*}{ TABLE 1} & \multicolumn{4}{|c|}{$\begin{array}{l}\text { Clinical features and pulmonary function indices } \\
\text { at presentation, compared between patients } \\
\text { dying within } 2 \text { yrs and those dying after more } \\
\text { than } 2 \text { yrs of follow-up }\end{array}$} \\
\hline & & Early deaths & Late deaths & $\begin{array}{c}\text { Statistical } \\
\text { significance }\end{array}$ \\
\hline \multicolumn{2}{|l|}{ Subjects $n$} & 31 & 31 & \\
\hline \multicolumn{2}{|l|}{ Age yrs } & $53.9 \pm 10.4$ & $56.3 \pm 6.4$ & NS \\
\hline \multicolumn{2}{|c|}{ Males/females $n$} & $23 / 8$ & $38 / 4$ & $p=0.06$ \\
\hline \multicolumn{2}{|c|}{ Dyspnoea duration months } & $24(2-120)$ & $9.5(0-65)$ & $p=0.001$ \\
\hline \multicolumn{2}{|c|}{ CPI unadjusted units } & $55.3 \pm 13.4$ & $46.7 \pm 7.8$ & $p<0.001$ \\
\hline \multicolumn{2}{|c|}{ FEV $1 \%$ pred } & $67.2 \pm 16.6$ & $79.8 \pm 12.1$ & $p<0.0005$ \\
\hline \multicolumn{2}{|c|}{ FVC \% pred } & $62.0 \pm 20.0$ & $78.7 \pm 14.3$ & $p<0.0001$ \\
\hline \multicolumn{2}{|c|}{ DL,CO \% pred } & $39.4 \pm 14.5$ & $45.8 \pm 11.3$ & $p=0.04$ \\
\hline \multicolumn{2}{|l|}{$\mathrm{PO}_{2} \mathrm{kPa}$} & $8.8 \pm 1.8$ & $10.4 \pm 1.4$ & $p<0.0005$ \\
\hline
\end{tabular}

Data are presented as mean \pm SD or median (range), unless otherwise stated $\mathrm{CPI}$ : composite physiological index; FEV1: forced expiratory volume in $1 \mathrm{~s}$; $\%$ pred: \% predicted; FVC: forced vital capacity; DL,CO: diffusing capacity of the lung for carbon monoxide; $\mathrm{PO}_{2}$ : oxygen tension; NS: not significant. Reproduced from [21] with permission from the publisher. 
course of $<1$ month; 2) new pulmonary infiltrates seen on a chest radiograph; and 3) worsening hypoxaemia, defined as $>10 \mathrm{mmHg}$ reduction in arterial oxygen tension; 4) all in the absence of infection or heart failure [28]. Diffuse alveolar damage superimposed on underlying usual interstitial pneumonia is the most commonly described finding when surgical lung biopsy is performed [29].

Acute exacerbation of IPF is often managed using high-dose corticosteroids, although there are no data from controlled trials to support their efficacy. Cyclosporin A has been studied, but no convincing evidence of advantage has been demonstrated [30-32]. Anticoagulant therapy administered over a 3 -yr period has been associated with a lower mortality from acute exacerbation, compared to untreated patients $(18 \%$ versus $71 \%$ ) [26]. A preventive role has also been suggested for antifibrotic therapy, as the administration of pirfenidone has been associated with significant reductions in the risk of acute exacerbation [25].

\section{VENTILATION}

The occurrence of an acute life-threatening hypoxaemia during the course of IPF may lead to consideration of ventilatory support. However, patients with IPF admitted to the intensive care unit with acute respiratory failure needing ventilation have a very poor prognosis [33]. In the period 1980-2000, a group of studies highlighted the inadequacy of mechanical ventilation in acute respiratory failure in IPF. Pooled data showed an aggregated mortality of $87 \%$ (118 out of 135), and short-term mortality (within 3 months of hospital discharge) of $94 \%$ [27, 32-38]. A study of seven patients with IPF receiving mechanical ventilation found that the elastance and the resistance of the respiratory system was markedly increased and correlated with the degree of hypercapnia. These phenomena may contribute to the observed absence of respiratory improvement in this patient group [36].

\section{PALLIATIVE CARE}

Management of cough, which typically causes difficulty with falling asleep or awakening during the night, is a significant factor in maintaining overall quality of life for the IPF patient $[1,39]$. Codeine and stronger opioids are effective antitussives, but their use is not supported by randomised clinical studies. An open case series study assessing the effect of low dose diamorphine on dyspnoea in 11 elderly patients with advanced IPF has suggested that in IPF, oral morphine may cause a reduction in troublesome cough. However, the immediate effect on cough was not measured [40].

Palliative care aims to improve the quality of life of patients and their families facing the problems associated with lifethreatening illness. This is achieved through early identification, assessment and management of pain and other disease-related problems, whether physical, psychosocial or spiritual [41]. The American Thoracic Society policy statement on palliative care for patients with respiratory diseases and critical illnesses describes a management process that is both individualised and integrated. In this model, palliative care begins when a patient becomes symptomatic, is usually concurrent with restorative and life-prolonging care, and is designed to meet the specific needs of the patient and family. This should be done through careful assessment of their values, goals and priorities, as well as their cultural context and spiritual needs. A patient support group may encourage and support family involvement in planning and providing care to the extent desired by the patient [42].

Advance care planning allows patients to make decisions about life-prolonging therapies, at a point in their life when they have time to consider the issues. Preferences for care and advance directives should be discussed in the outpatient setting or very soon after hospital admission [43]. Advance directives as part of a comprehensive approach are desired by most people, require physician initiative, and can be achieved during a regular office visit [44]. Patients who wish to make a written advance directive (e.g. a durable power of attorney or a living will), or who wish to express a preference regarding use of life-supporting interventions (e.g. intubation or cardiopulmonary resuscitation), should be encouraged to engage in discussions with their surrogates and physicians so that there is a clear understanding of the patient's goals [42].

\section{SUMMARY AND CONCLUSIONS}

IPF has a variable clinical course which makes it difficult to treat. Management of IPF requires an orderly approach with regular evaluations and the implementation of pharmacological and nonpharmacological modalities. Nonpharmacological strategies have a significant role to play in minimising the impact of IPF on patients, families and carers. The interventions available include oxygen therapy, transplantation, rehabilitation, acute care of exacerbations, and palliation. This diversity requires the participation of a range of healthcare professionals, cooperating in the context of an integrated management plan. Patient support groups are critical in encouraging and supporting the patient and family to set goals and plan accordingly.

\section{STATEMENT OF INTEREST}

None declared.

\section{ACKNOWLEDGEMENTS}

This issue of the European Respiratory Review contains proceedings of a satellite symposium held at the 20th ERS Annual Congress, 2010, which was sponsored by InterMune Inc. The authors were assisted in the preparation of the text by professional medical writers at IntraMed International (Milan, Italy); this medical writing support was funded by InterMune Inc.

\section{REFERENCES}

1 American Thoracic Society. Idiopathic pulmonary fibrosis: diagnosis and treatment. International consensus statement. American Thoracic Society (ATS), and the European Respiratory Society (ERS). Am J Respir Crit Care Med 2000; 161: 646-664.

2 Hubbard R, Johnston I, Britton J. Survival in patients with cryptogenic fibrosing alveolitis: a population-based cohort study. Chest 1998; 113: 396-400.

3 Christie JD, Edwards LB, Kucheryavaya AY, et al. The Registry of the International Society for Heart and Lung Transplantation: twenty-seventh official adult lung and heart-lung transplant report - 2010. J Heart Lung Transplant 2010; 29: 1104-1118.

4 Turner-Warwick M, Burrows B, Johnson A. Cryptogenic fibrosing alveolitis: clinical features and their influence on survival. Thorax 1980; 35: 171-180.

5 Bradley B, Branley HM, Egan JJ, et al. Interstitial lung disease guideline: the British Thoracic Society in collaboration with the 
Thoracic Society of Australia and New Zealand and the Irish Thoracic Society. Thorax 2008; 63: Suppl. 5, v1-v58.

6 Griffiths TL, Burr ML, Campbell IA, et al. Results at 1 year of outpatient multidisciplinary pulmonary rehabilitation: a randomised controlled trial. Lancet 2000; 355: 362-368.

7 Ong KC, Wong WP, Jailani AR, et al. Effects of a pulmonary rehabilitation programme on physiologic and psychosocial outcomes in patients with chronic respiratory disorders. Ann Acad Med Singapore 2001; 30: 15-21.

8 Emery CF, Schein RL, Hauck ER, et al. Psychological and cognitive outcomes of a randomized trial of exercise among patients with chronic obstructive pulmonary disease. Health Psychol 1998; 17: 232-240.

9 Holland AE, Hill CJ, Conron M, et al. Short term improvement in exercise capacity and symptoms following exercise training in interstitial lung disease. Thorax 2008; 63: 549-554.

10 Ries AL, Bauldoff GS, Carlin BW, et al. Pulmonary Rehabilitation: Joint ACCP/AACVPR Evidence-Based Clinical Practice Guidelines. Chest 2007; 131: 4S-42S.

11 Man WD, Polkey MI, Donaldson N, et al. Community pulmonary rehabilitation after hospitalisation for acute exacerbations of chronic obstructive pulmonary disease: randomised controlled study. BMJ 2004; 329: 1209.

12 Clark M, Cooper B, Singh S, et al. A survey of nocturnal hypoxaemia and health related quality of life in patients with cryptogenic fibrosing alveolitis. Thorax 2001; 56: 482-486.

13 Douglas WW, Ryu JH, Schroeder DR. Idiopathic pulmonary fibrosis: impact of oxygen and colchicine, prednisone, or no therapy on survival. Am J Respir Crit Care Med 2000; 161: $1172-1178$.

14 De VJ, Kessels BL, Drent M. Quality of life of idiopathic pulmonary fibrosis patients. Eur Respir J 2001; 17: 954-961.

15 American Thoracic Society/European Respiratory Society International Multidisciplinary Consensus Classification of the Idiopathic Interstitial Pneumonias. Am J Respir Crit Care Med 2002; 165: 277-304.

16 Thabut G, Mal H, Castier Y, et al. Survival benefit of lung transplantation for patients with idiopathic pulmonary fibrosis. J Thorac Cardiovasc Surg 2003; 126: 469-475.

17 Hosenpud JD, Bennett LE, Keck BM, et al. Effect of diagnosis on survival benefit of lung transplantation for end-stage lung disease. Lancet 1998; 351: 24-27.

18 Raghu G. The Development of Evidence-Based Guidelines of The ATS, ERS, JRS and ALAT Joint Task Force For The Management of IPF: New Diagnostic Criteria, Natural Course And Approach To The Diagnosis Of IPF. Presentation at ATS 2010 International Conference, 14-19 May 2010, New Orleans. http://conference. thoracic.org/Programs/past-conference.php

19 Egan TM, Murray S, Bustami RT, et al. Development of the new lung allocation system in the United States. Am J Transplant 2006; 6: $1212-1227$.

20 Russo MJ, Iribarne A, Hong KN, et al. High lung allocation score is associated with increased morbidity and mortality following transplantation. Chest 2010; 137: 651-657.

21 Latsi PI, du Bois RM, Nicholson AG, et al. Fibrotic idiopathic interstitial pneumonia: the prognostic value of longitudinal functional trends. Am J Respir Crit Care Med 2003; 168: 531-537.

22 Mogulkoc N, Brutsche MH, Bishop PW, et al. Pulmonary function in idiopathic pulmonary fibrosis and referral for lung transplantation. Am J Respir Crit Care Med 2001; 164: 103-108.

23 Collard HR, King TE Jr, Bartelson BB, et al. Changes in clinical and physiologic variables predict survival in idiopathic pulmonary fibrosis. Am J Respir Crit Care Med 2003; 168: 538-542.

24 Orens JB, Estenne M, Arcasoy S, et al. International guidelines for the selection of lung transplant candidates: 2006 update - a consensus report from the Pulmonary Scientific Council of the
International Society for Heart and Lung Transplantation. J Heart Lung Transplant 2006; 25: 745-755.

25 Azuma A, Nukiwa T, Tsuboi E, et al. Double-blind, placebocontrolled trial of pirfenidone in patients with idiopathic pulmonary fibrosis. Am J Respir Crit Care Med 2005; 171: 1040-1047.

26 Kubo H, Nakayama K, Yanai M, et al. Anticoagulant therapy for idiopathic pulmonary fibrosis. Chest 2005; 128: 1475-1482.

27 Kim DS, Park JH, Park BK, et al. Acute exacerbation of idiopathic pulmonary fibrosis: frequency and clinical features. Eur Respir J 2006; 27: 143-150.

28 Kondoh Y, Taniguchi H, Kawabata Y, et al. Acute exacerbation in idiopathic pulmonary fibrosis. Analysis of clinical and pathologic findings in three cases. Chest 1993; 103: 1808-1812.

29 Churg A, Muller NL, Silva CI, et al. Acute exacerbation (acute lung injury of unknown cause) in UIP and other forms of fibrotic interstitial pneumonias. Am J Surg Pathol 2007; 31: 277-284.

30 Okamoto T, Ichiyasu H, Ichikado K, et al. [Clinical analysis of the acute exacerbation in patients with idiopathic pulmonary fibrosis]. Nihon Kokyuki Gakkai Zasshi 2006; 44: 359-367.

31 Homma S, Sakamoto S, Kawabata M, et al. Cyclosporin treatment in steroid-resistant and acutely exacerbated interstitial pneumonia. Intern Med 2005; 44: 1144-1150.

32 Al-Hameed FM, Sharma S. Outcome of patients admitted to the intensive care unit for acute exacerbation of idiopathic pulmonary fibrosis. Can Respir J 2004; 11: 117-122.

33 Blivet S, Philit F, Sab JM, et al. Outcome of patients with idiopathic pulmonary fibrosis admitted to the ICU for respiratory failure. Chest 2001; 120: 209-212.

34 Molina-Molina M, Badia JR, Marin-Arguedas A, et al. [Outcomes and clinical characteristics of patients with pulmonary fibrosis and respiratory failure admitted to an intensive care unit. A study of 20 cases]. Med Clin (Barc) 2003; 121: 63-67.

35 Saydain G, Islam A, Afessa B, et al. Outcome of patients with idiopathic pulmonary fibrosis admitted to the intensive care unit. Am J Respir Crit Care Med 2002; 166: 839-842.

36 Nava S, Rubini F. Lung and chest wall mechanics in ventilated patients with end stage idiopathic pulmonary fibrosis. Thorax 1999; 54: 390-395.

37 Stern JB, Mal H, Groussard O, et al. Prognosis of patients with advanced idiopathic pulmonary fibrosis requiring mechanical ventilation for acute respiratory failure. Chest 2001; 120: 213-219.

38 Fumeaux T, Rothmeier C, Jolliet P. Outcome of mechanical ventilation for acute respiratory failure in patients with pulmonary fibrosis. Intensive Care Med 2001; 27: 1868-1874.

39 Swigris JJ, Kuschner WG, Jacobs SS, et al. Health-related quality of life in patients with idiopathic pulmonary fibrosis: a systematic review. Thorax 2005; 60: 588-594.

40 Allen S, Raut S, Woollard J, et al. Low dose diamorphine reduces breathlessness without causing a fall in oxygen saturation in elderly patients with end-stage idiopathic pulmonary fibrosis. Palliat Med 2005; 19: 128-130.

41 World Health Organization. WHO Definition of Palliative Care 2005. www.who.int/cancer/palliative/definition/en/print.html Date last accessed: December 3, 2010.

42 Lanken PN, Terry PB, Delisser HM, et al. An official American Thoracic Society clinical policy statement: palliative care for patients with respiratory diseases and critical illnesses. Am J Respir Crit Care Med 2008; 177: 912-927.

43 Wenger NS, Oye RK, Bellamy PE, et al. Prior capacity of patients lacking decision making ability early in hospitalization: implications for advance directive administration. The SUPPORT Investigators. Study to Understand Prognoses and Preferences for Outcomes and Risks of Treatments. J Gen Intern Med 1994; 9: 539-543.

44 Emanuel LL, Barry MJ, Stoeckle JD, et al. Advance directives for medical care - a case for greater use. $N$ Engl J Med 1991; 324: 889-895. 